\title{
Trust, Communication and Contracts: An Experiment
}

\author{
by \\ Avner Ben-Ner ${ }^{+}$and Louis Putterman ${ }^{++}$
}

\begin{abstract}
In the one-shot trust or investment game without opportunities for reputation formation or contracting, economic theory predicts no trusting because there is no incentive for trustworthiness. Under these conditions, theory predicts (a) no effect of pre-play communication, and (b) universal preference for moderate cost binding contracts over interacting without contracts. We introduce the opportunities to engage in pre-play communication and to enter binding or non-binding contracts, and find (a) communication increases trusting and trustworthiness, (b) contracts are largely unnecessary for trusting and trustworthy behaviors and are eschewed by many players, and (c) more trusting leads to higher earnings, and (d) both trustors and trustees favor "fair and efficient" proposals over the more unequal proposals predicted by theory.
\end{abstract}

Keywords: trust game, trust, trustworthiness, reciprocity, commitment, communication.

JEL codes: C72, C91, D63

This version: November, 2006

\footnotetext{
${ }^{+}$Professor, Industrial Relations Center, Carlson School of Management, University of Minnesota, Minneapolis, MN. abenner@,csom.umn.edu

${ }^{++}$Professor of Economics, Brown University, Providence, RI. Louis_Putterman@Brown.Edu.
} 


\section{Trust, Communication and Contracts: An Experiment*}

\section{by Avner Ben-Ner and Louis Putterman}

\section{Introduction}

Imagine a rational and self-interested individual facing the following choice: (1) entrust money into the hands of another individual with the knowledge that the money will triple when it reaches the other individual, but that individual has the liberty to return any proportion of the amount received, including none, or (2) write a binding contract at modest cost that specifies how much of the money received the other individual must return. It doesn't take a lot of economic education to know the right answer. Or does it? Many individuals who faced this choice as participants in our experiment at the University of Minnesota chose trust over a contract and successfully doubled their earnings.

Beginning with the investment game of Berg, Dickhaut and McCabe (1995, hereafter BDM), a burgeoning literature has established unequivocally the existence of behavior that is at odds with the prediction of standard economic reasoning in the context of one-shot situations. ${ }^{1}$ But the literature has shown that there is also a lot of distrust and untrustworthy behavior, so it was not clear on balance whether it is individually or socially sensible to trust. We devised a series of experiments to extend the frontiers of our understanding in two directions. First, we consider the influence of parties' abilities to communicate prior to engaging in exchange. In our experiments, subjects entered into a series of one-shot interactions by computer with unidentified partners in a different room, with communication opportunities varying from (a) zero prior communication to (b) single-round numerical proposals and responses to (c) multi-round proposals and responses and finally to (d) chat room communication of typed messages followed by numerical proposals and responses.

\footnotetext{
* We thank the Russell Sage Foundation for support of this research. We wish to thank Ting Ren for critical research assistance including data management and analysis. We are grateful to Freyr Halldorsson and Ting Ren for their help in planning and carrying out the experiments. We thank participants in the International Economic Association workshop on "Corporate Social Responsibility and Corporate Governance: The Contribution of Economic Theory and Related Disciplines," in Trento, Italy, and in an Economics Workshop at Cornell University for helpful comments.

${ }^{1}$ For recent examples, see the special issue of the Journal of Economic Behavior and Organization, on "Trust and Trustworthiness," vol. 55, no. 4, 2004.
} 
Second, we investigate the choice between costly contractual enforcement and reliance on trust by giving subjects the option of entering into costly contracts that let them capture some of the surplus that is potentially available through trust but without reliance on trust. We investigate the conditions-including the kinds of communication possibilities that are present - that determine when a pair of individuals selects to forego some of the potential surplus in favor of contractual guarantees, and when they rely on trust instead. Further, we give subject pairs the option of entering into either a contract that contains no penalty provisions and that is therefore no more than a way of solemnizing an agreement, or a more expensive contract with penalty provisions rendering breaches of promise unprofitable. The inclusion of penalty-free contracts allows us to study the value subjects place on formal agreements, and the degree to which concluding one alters their behaviors.

We find that subjects in the trustor role on average sent significantly more of their endowments to those in the trustee role when there was an opportunity for prior communication, and that this was most strongly the case when that communication was verbal, i.e., in the form of text messages. There is also more trustworthiness, that is, larger proportions of amounts received are returned, with communication. Thus, communication allowed subjects to appropriate more of the potential surplus from their interactions. Our finding that communication can elevate trust and the gains from trust is important for understanding both the effects of communication (which in theory should be mere "cheap talk") and the nature of trust.

Another interesting finding is that about half of all interactions led to equal earnings by trustor and trustee, although trustees' incentives were to keep any money sent to them. This strongly suggests the pull of equal division as a focal point to our subjects. Moreover, the proportion of fair and efficient outcomes is far higher than that in BDM even when pre-play communication is absent, and we attribute this in part to the explicit manner in which choices and outcomes were presented in the interactions table that we designed to facilitate exchange of proposals - in other words, a kind of framing effect. ${ }^{2}$

The paper proceeds as follows. In Section 2, we discuss trust, communication and contracts in general and with reference to the recent literature. In Section 3, we give

\footnotetext{
${ }^{2}$ Note that we conducted our experiment at the same university as BDM.
} 
details about our experimental design. Section 4 discusses our findings, and Section 5 concludes the paper.

\section{Trust, Communication and Contracts}

In everyday usage, to say that party $A$ trusts party $B$ is to make a statement about $A$ 's favorable mental disposition toward $B$. However, the idea of trust is usually applied in economics with a more specific meaning. How much, if at all, $A$ trusts $B$ is indicated by the degree to which $A$ displays a willingness to engage with $B$ in an interaction that has the potential to benefit both $A$ and $B$, but that would end up harming $A$ were $B$ to respond in a purely self-regarding fashion. $A$ manifests trust by making himself vulnerable to $B$ 's response in the hope or expectation that $B$ will act at least in part with $A$ 's interest in mind. ${ }^{3}$

Consider the interaction between a homeowner $A$ and a house painter $B$. $A$ and $B$ may come to an agreement regarding what walls are to be painted, in what manner, on what schedule, and at what price. However, unless $A$ is to stand at $B$ 's side paying out a small piece of change at each stroke of the brush or roller, their interaction is not perfectly synchronized, and each is at risk of opportunism by the other. $A$ could pay $B$ up front, risking the possibility that $B$ will drag his feet on the job, do sloppy work, or even close his business and disappear. $B$ could paint the house first, risking having $A$ refuse to pay when the job is completed. If the job as a whole is a big one, breaking up the payment and making its parts contingent on completing portions of the work is often part of the solution adopted. But usually either or both parties will end up taking some risks. The first payment will be made, or the job will be started, without absolute guarantees, with at least one party trusting the other, due to some combination of reputational and other factors.

The problem of trust has been studied in the lab using the protocol developed by BDM, wherein $A$ and $B$ are each endowed with $\$ 10, A$ moves first and can send $0, \$ 1, \ldots$ $\$ 10$ to $B$, the experimenter triples what $A$ sends, and $B$ moves last and can send $A$

\footnotetext{
3 "To say 'A trusts B' means that A expects B will not exploit a vulnerability A has created for himself by taking the action" (James, 2002). If A entered the relationship with the sole aim of aiding B, A's act would be one of altruism, not trust. If A "trusts" B because A knows that B has (selfish) incentives to do what is in the interest of A, this also fails to satisfy our definition. For similar definitions, see Bohnet and Zeckhauser (2004), Eckel and Wilson (2004), and Ben-Ner and Putterman (2001).
} 
between 0 and the tripled amount. Standard economic theory, which assumes that subjects are rational and that their goals are to maximize their own payoffs (without social constraints), identifies as the unique equilibrium in one-shot or finitely repeated play that $A$ sends nothing and $B$ returns nothing. However, the game becomes more interesting if some players are of a type characterized by a social preference. For example, if some players obtain disutility should they fail to reciprocate the trust or kindness of others by returning more than was sent, the task of a payoff-maximizing player $A$ is to estimate the likelihood that her counterpart $B$ is of this type, the task of a reciprocator-type $B$ is to attempt to signal his type if the opportunity to do so is available, and the task of a payoff-maximizing $B$ is to attempt to send a false signal of being a reciprocator, if possible.

\section{Communication}

In laboratory experiments, face-to-face communication has been found to be one of the most powerful ways of increasing cooperation. Isaac and Walker (1988) found that pre-play communication led their experimental subjects to contribute considerably more to a public good. Their study is one of 37 that report 130 different experimental treatments whose results Sally (1995) entered in multivariate regressions to study which treatment variables best account for differing levels of cooperation and free riding in public goods games. Sally concluded that face-to-face communication was the single strongest of the treatment variables studied. Ostrom, Walker and Gardner (1992) found that the combination of communication and the ability to sanction other group members led to significantly higher efficiencies in their common pool resource experiment.

A problem with interpreting the impact of face-to-face communication is that it adds a number of potentially separable elements to treatments involving subject anonymity and absence of communication, making it difficult to know what accounts for its influence. When subjects communicate face to face, anonymity is lost, which introduces the possible influence of identity (one learns the counterpart's gender, race, height, etc.). ${ }^{4}$ Concerns about possible post-interaction reward or punishment arise.

\footnotetext{
${ }^{4}$ The effects of identity may be substantial and quite different across identity dimensions, as Ben-Ner, McCall, Stephane and Wang (2006) found in dictator game experiments.
} 
Psychological costs may also be altered: a subject may feel greater obligation to trust, or to be trustworthy towards, a concrete other. Face-to-face meetings also make possible verbal communication, in which promises can be delivered. Commitment, sympathy, and other emotions can also be conveyed by vocal intonation, facial expression, and body language. Interpersonal attraction, aversion, or bonding may result from physical proximity.

To understand better what lies behind the effects of face-to-face communication, researchers including Wilson and Sell (1997), Frohlich and Oppenheimer (1998), Brosig, Ockenfels and Weimann (2003) and Bochet, Page and Putterman (2006) have conducted voluntary contribution mechanism (VCM) experiments in which other forms of communication were substituted for face-to-face discussion. Of particular interest for our purposes are Bochet et al.'s and Frohlich and Oppenheimer's treatments in which subjects could communicate text messages in a chat room or by e-mail, and Wilson and Sell's and Bochet et al.'s treatments in which subjects could relay non-binding possible choices in numerical form, including (in the second experiment) time for iterative reactions before each binding decision stage. The chat and e-mail treatments generated more cooperation than no-communication baselines, but less than face-to-face communication. The numerical communication treatments failed to increase average cooperation, although Bochet and Putterman (2006) show that subjects treated one another's messages as serious attempts at coordination.

There have been fewer experiments with pre-play communication in trust games, and none in which both parties could exchange proposals or verbal messages. Malhotra and Murnighan (2002) had a computer program posing as trustee sometimes propose a non-binding contract for mutual cooperation, and found that trustors who agreed to such a contract sent more to their "counterpart." Buchan, Croson and Johnson (2006) allow subjects to engage in communication before playing trust games, but theirs is a manipulation of social distance prior to informing subjects of their decision task, so there is no task-relevant communication. Fehr and Rockenbach (2003), Houser, Xiao, McCabe and Smith (2005) and Rigdon (2005) conducted games in which trustors could suggest amounts to be returned by their trustee counterparts and in some conditions threaten punishment should they not do so. Rigdon's subjects could reject or accept proposals. In 
none of their treatments is communication fully two-sided, though, and their papers focus mainly on the effects of threatening punishment, rather than on the effects of differing proposal terms. Charness and Dufwenberg (forthcoming) permit either trustor or trustee, but not both, to send a single message in a binary trust game. They find that the amounts of both trusting and trustworthiness increase significantly when trustees can send messages, but are not influenced by letting trustors send them.

What can communication be expected to do to trusting and trustworthiness? If rational and self-interested subjects know that after communication they may enter into a binding contract they will take communication seriously for coordination and bargaining. Otherwise they'll treat all communication as pointless cheap talk - unless they believe that their counterparts may be prone to keeping promises due to holding social or procedural preferences.

We asked our subjects to play trust games with forms of numerical announcements that resemble those in Wilson and Sell and in Bochet et al.'s "numerical cheap talk" treatment, and with text communication resembling that in Frohlich and Oppenheimer and in Bochet et al.'s chat room treatment. Comparing trust game play without prior announcements to that with numerical announcements lets us investigate whether announcements help partners to coordinate or to achieve trust, while comparing treatments with and without text messages provides indications of when and how the exchange of verbal messages can increase trust.

\section{Contracting}

Entering into a contract can be a substitute for trust. Whereas it is in $B$ 's material interest to act in an untrustworthy fashion toward $A$ when $A$ takes trusting actions in a one-shot trust game, a contract with sufficiently sure and costly penalties for nonfulfillment can transform the interaction into one that is both mutually beneficial and that both have material incentives to execute. As a simple example, consider the trust game above and suppose, for simplicity, that a contract can be written and enforced for a cost C, shared equally between $A$ and $B$, under which any violator will be fined the amount that brings his/her overall earnings to zero. Let $A$ and $B$ agree that $A$ will send $B \$ 10$ and be given back $\$ 20$. Then if, as in BDM, $B$ also has an initial endowment of \$10, earnings 
will be $\left(\$ 20-\frac{1}{2} \mathbf{C}, \$ 20-1 / 2 \mathbf{C}\right)$ if the contract is carried out, and if either party violates the contract, that person will earn 0 . Then as long as $\mathbf{C}<\$ 20$, the parties value earnings, and there are no conflicting emotional or other considerations, the contract can be expected to be preferred to no contract and no trust, and it would be fulfilled even in the complete absence of trust. Of course, both would prefer earnings of $(\$ 20, \$ 20)$, but both prefer $(\$ 20-1 / 2 \mathbf{C}, \$ 20-1 / 2 \mathbf{C})$ to $(\$ 10, \$ 10)$, and $(\$ 20, \$ 20)$ is unachievable without trust.

Sometimes trusting is the only way to achieve the potential gains from an interaction. At other times, costly contracts are available but are of questionable desirability because of their cost. Suppose, in the above example, that $\mathbf{C}=\$ 18$, so that net earnings after carrying out the contract would be $\$ 11$ for each party, a gain of $\$ 1$ for each over the no-trade situation. Then if they are sufficiently confident that the agreement will be adhered to even without a contract, $A$ and $B$ will prefer to rely exclusively on trust. Suppose, for instance, that each believes the chances are $80 \%$ that his or her counterpart will adhere to an agreement that $A$ send $B \$ 10$ and $B$ return to $A \$ 20$. Suppose, further, that with the remaining $20 \%$ probability $A$ sends nothing or $B$ returns nothing, and that $A$ and $B$ each plan to fulfill his/her own part (in $B$ 's case, provisional upon $A$ doing so). In this case, $A$ 's expected earnings from the interaction without contract are $\$ 16(=0.2 * 0+$ $0.8 * \$ 20)$ and $B$ 's expected earnings are $\$ 18(=\$ 10+[0.2 * 0+0.8 * \$ 10])$. Since each expects earnings of $\$ 11$ with a contract, they will not enter into a contract unless they are very risk averse.

There are some instances in which either the reliability of contract enforcement or the penalties associated with noncompliance are too low to make a contract self-enforcing in terms of material incentives alone. For instance, the penalty bringing earnings to zero might be brought to bear with only $50 \%$ probability, or a penalty may be imposed with certainty but may take away only $50 \%$ of the violator's gain from breaching the contract. Nevertheless, the parties may wish to enter into a contract as a way to formalize their agreement, e.g., if they believe there to exist types who are averse to breaking their word (a possible social preference). Sally (1995) found that more cooperation was achieved in social dilemma experiments in which experimenters suggested to subjects, prior to communication, that they could exchange promises. Malhotra and Murnighan (2002) found that when the trustee (who unbeknownst to the trustor was actually a programmed 
virtual agent) proposed a non-binding contract of trusting and trustworthiness, trustors were significantly more likely to trust in their binary trust game. Bochet and Putterman (2005) found that giving subjects the opportunity to select a statement promising to contribute to a public good led to higher average contributions in a condition in which group members also had the ability to sanction others using costly material punishments. In our experiment, we study the value subjects attach to contracts independent of their material impact on payoffs by making contracts without penalties available but costly to enter into.

\section{Experimental Design and Predictions}

Our experiment consisted of a pre-laboratory sign-up portion that took most subjects 30-45 minutes to complete, and a laboratory portion lasting about one hour. In the present paper, we discuss only the laboratory decisions. Subjects arrived for that portion of the experiment at the planned time and location at various computer labs on the University of Minnesota-Twin Cities campus, were assigned to a room with (typically 15-20) other subjects with whom no communication was permitted and to be either trustor (role $A$ ) or trustee (role $B$ ), read along with a room experimenter brief instructions and read more detailed and specific instructions on screen, and answered on the computer practice questions to test their comprehension. They then engaged in a series of seven one-shot trust games with unknown individuals sitting in a different room in a different building, completed a paper and pencil cognitive ability test, and answered a few debriefing questions.

All trust games played in the laboratory portion had the same underlying structure as in BDM. Individuals assigned roles $A$ and $B$ were each credited with ten "experiment dollars" $(E \$)$, which converted to real dollars at the rate $E \$ 1=\$ 0.14$ at the end of the session. Subject $A$ was asked to choose a whole number of experiment dollars, $E \$ \mathrm{X}_{\mathrm{a}} \in$ $(0,1, \ldots, 10)$, to send to subject $B$ on the understanding that $B$ would receive triple the amount sent and could send back any part of that, including nothing. Thus, $A$ would earn with certainty any part of the $E \$ 10$ she kept and could additionally earn an amount 
between 0 and $E \$ 30$, depending on $B$ 's choice, while $B$ would earn between $E \$ 10$ and $E \$\left(10+3 \mathrm{X}_{\mathrm{a}}-\mathrm{X}_{\mathrm{b}}\right)$, where $\mathrm{X}_{\mathrm{b}} \leq 3 \mathrm{X}_{\mathrm{a}}$ is the amount $B$ sends to $A .^{5}$

To facilitate communication of proposals and counterproposals, subjects were shown Figure 1, in which each of the eleven row headings lists an amount that could be sent by $A$, these being restricted to the integers, and each of the seven column headings lists a proportion of the amount received that could be returned by $B$, these being restricted to sixths of the amount received $(0,1 / 6,1 / 3$, etc.). In the baseline trust game involving neither numerical nor verbal pre-play communication, choices were registered by $A$ clicking on a row heading, causing the row to be highlighted on the screens of both $A$ and $B$, and then $B$ clicking on a column heading, causing the associated row and column to become highlighted. In games with numerical communication, rows and columns that were clicked on became highlighted as a way of communicating proposals, with $A$ first proposing (by clicking and highlighting) both a row and a column, then $B$ proposing a row and column. Possible decisions were framed as " $A$ sends $B$ a number of experiment dollars" (e.g., " $A$ sends $B E \$ 3$ ") and " $B$ sends $A$ a fraction of the amount received" (for example " $B$ sends 50\%") To make sure that subjects understood the implications of their choices for the payout of their interaction, the table's cells list both the experiment dollar amount that $B$ is sending $A$ and (below and in brackets) the implied payouts to $A$ and $B$, including $B$ 's $\$ 10$ endowment (which $B$ always retains).

Our subjects engaged in a series of seven interactions, each with a new and anonymous partner in a room other than the subject's. ${ }^{6}$ A total of 194 subjects took part in a total of seven sessions of the design reported here. We describe the five interaction conditions that will be analyzed, in the order in which they were conducted. ${ }^{7}$

\footnotetext{
${ }^{5}$ The fact that at least $E \$ 10$ is guaranteed to $B$ more or less eliminates the possibility that $A$ sends to $B$ out of fairness, although altruism and efficiency (a desire to maximize the size of the pie) cannot be ruled out as motives. The possible confounding of trust or reciprocity with altruism has received attention in several recent papers including Cox (2004). We plan to investigate altruism and fairness concerns in our data elsewhere using relevant responses to the pre-lab survey portion.

${ }^{6}$ Subjects were recruited from a large cross-section of the University of Minnesota undergraduate population and reported directly to different rooms, and were dismissed at different times, so the chance they would know or even encounter those participating in the opposite role was quite small.

${ }^{7}$ In interactions 5 and 7, subjects were given information about their anonymous counterparts' gender, ethnic/racial group, family religious preference, and other characteristics. Analysis of these interactions is beyond the scope of the present paper.
} 
1. Simple Trust Game. In this interaction, $A$ chose a row, then $B$ a column, without prior proposals or communication.

2. Single Proposal. $A$ was asked to click on a row and column, thereby proposing a possible way the interaction could be conducted. $B$ was shown $A$ 's choices and asked to click on a row and column. As pre-announced to them, if $B$ chose the same row and column as $A$, they were offered the chance to enter into a contract, as follows (see Figure 2, which diagrams the possible decision sequences). First, both $A$ and $B$ were asked to choose (simultaneously and without communication) between a contract and no contract. If both said yes, at least a contract without penalties was entered into. If at least one said no, there was no contract, and they proceeded to make their decisions, as in interaction 1. If both subjects said yes to the first question, they were asked if they wanted a contract with penalties. If both said yes, they entered into such a contract; if at least one said no, they remained with a contract without penalties. Possible outcomes of the communication stage were thus (a) the two proposals do not match (no agreement), (b) an agreement on proposals but no contract, (c) agreement on proposals and a contract without penalties, and (d) agreement on proposals and a contract with penalties. Once the question of contracts was concluded, the subjects proceeded to their binding choices - i.e., $A$ clicking on a row heading, highlighting the row, and then $B$ clicking on a column heading, highlighting the column. Regardless of whether an agreement or contract was reached, subjects were reminded at the binding decision stage that $A$ could click on any row and $B$ could click on any column. In this and other interactions where agreements and contracts were possible, the subjects were informed of the possible actions regarding agreements, contracts, and penalties as well as how they may be reached in advance, at the start of the interaction.

3. Multiple Proposals. The process is the same as in Single Proposal, except that if $B$ does not choose the same proposal as $A$ the first time around, $A$ and $B$ can each make up to two more proposals and counterproposals (for a total of three each). The process ends either as soon as $A$ and $B$ have consecutively highlighted the same row and column, or after $B$ 's third counterproposal. If the same row and column are highlighted consecutively, 
whether at the last proposal or before, the subjects are offered the chance to enter into a contract; if not, they proceed to their binding choices without the opportunity to enter a contract. The same sequence of choices, first on at least a contract without penalties, then (if that has been chosen) on a contract with penalties, is followed, as above, and in the binding decision stage subjects are again reminded that they are free to choose any row and column.

\section{Chat plus Single Proposal. Before $A$ and $B$ clicked on rows and columns, they} exchanged text messages in a private chat room for four minutes. Their messages could be on any topic except that they were prohibited from disclosing their names (on penalty of forfeiting all payments) and from making threats about actions to be carried out after the experiment. When the chat period ended, $A$ and $B$ proceeded to an interaction identical to Single Proposal, including the possibility of entering one of the two kinds of contracts if $B$ concurred with what $A$ proposed. $^{8}$

\section{Counterpart History and Single Proposal. Before $A$ and $B$ interacted, each saw a} summary of his counterpart's play in the previous five interactions. For each interaction, a column indicated what $A$ and $B$ sent, whether a contract without or with penalties was agreed to, and if so whether the contract was violated. Once each had had a chance to review this information, they proceeded with an interaction identical to Single Proposal. (Figure 3 provides an example of the history screen seen by subject $A$.) ${ }^{9}$

A contract without penalties cost each party $E \$ 1$ or $E \$ 2$, depending on the experiment session, while one with penalties cost each twice that amount (hence, either $E \$ 2$ or $E \$ 4)$, regardless of whether penalties needed to be imposed. The penalty rate was $110 \%$ of whatever stipulated amount was not sent. For example, if $A$ agreed to send $E \$ 10$

\footnotetext{
${ }^{8}$ Note that no further exchange of chat messages was possible once the process of clicking on proposed rows and columns and making selections for or against contracts was begun.

${ }^{9}$ Note that subjects had no prior indication that their past actions might become known to future partners. On the contrary, having been informed that each interaction would be with a different partner and there being no mention that past actions might become known, subjects will most likely have been proceeding thus far on the assumption that past history would not affect future interactions. We analyze interactions 1 through 4 on that assumption.
} 
but actually sent $E \$ 9, E \$ 1.10$ was deducted from $A$ 's earnings for the interaction. If $B$ received $E \$ 20$, had agreed to return $50 \%$, but actually sent $E \$ 5, E \$ 5.50$ (= ([.5x $E \$ 20]$ $E \$ 5) \times 1.10)$ was deducted from $B$ 's earnings. Note that if a contract was agreed upon and $A$ sent a positive amount to $B, B$ was obligated to return the proportion agreed to even if the amount sent by $A$ fell short of that stipulated.

An example of exchanges for an entire session of the experiment including screen shots of what appears on the computer monitors of subjects in roles $A$ and $B$ can be found at http://webpages.csom.umn.edu/hrir/abenner/web/papers/ep/ep-01.pdf.

\section{Predictions and Hypotheses}

The predictions of economic theory under the assumptions that subjects are 1) concerned only with their own payoffs, 2) not guided by values and ethical concerns, 3) rational, and 4) assume that their counterparts in the experiment are like them in these respects, serve as a useful analytical benchmark. Under these assumptions (and assuming interactions are not repeated and that informational conditions make it impossible to invest in reputation), $B$ should send no money to $A$ regardless of how much he receives, absent a binding contract, and understanding this $A$ will send nothing to $B$, absent such a contract. $A$ and $B$ thus each keep their initial endowments and earn $E \$ 10$ from an interaction without a contract.

Under the same conventional assumptions, it also follows that (a) ability to make proposals, no matter how many, (b) concurring on the same proposal, (c) entering a contract without penalties, and (d) exchanging text messages, would make no difference. Only a binding contract can lead to positive sending and returning by $A$ and $B$. With contract costs of $E \$ 1$ or $E \$ 2$ for each subject, such a contract on a proposal such as $\left(\mathrm{X}_{\mathrm{a}}, \mathrm{X}_{\mathrm{b}}\right)=(E \$ 10, E \$ 20)$ can make both players substantially better off. Knowing this, $A$ should make a proposal that maximizes his surplus while giving $B$ a little over his fallback. ${ }^{10}$ With the restriction of $B$ 's return proportion to multiples of $1 / 6$, there is an unambiguous prediction that $A$ will propose a contract-with-penalties with terms $\left(\mathrm{X}_{\mathrm{a}}, \mathrm{X}_{\mathrm{b}}\right)$

\footnotetext{
${ }^{10}$ In received theory, B would also accept and implement a contract that leaves him neither better nor worse off than the alternative, but it can be argued that since a rational B could decide between the indifferent alternatives by a coin flip, offering at least an epsilon improvement gives a higher expected payoff to A.
} 
$=(E \$ 10, E \$ 25),{ }^{11}$ which gives net earnings after contract costs of $E \$ 1$ or $E \$ 2$ per player of either $(E \$ 24, E \$ 14)$ or $(E \$ 23, E \$ 13)$. Since there is no opportunity to agree on a counter-proposal, a rational payoff-maximizing $B$ will accept this proposal, and both will proceed to select a contract in general and a contract-with-penalties in particular. ${ }^{12}$ Neither multiple proposals nor chat change this prediction. To summarize, conventional economic theory predicts $\left(X_{a}, X_{b}\right)=(0,0)$ in interaction 1 and (assuming preference for the tie-breaking solution $)\left(\mathrm{X}_{\mathrm{a}}, \mathrm{X}_{\mathrm{b}}\right)=(E \$ 10, E \$ 25)$ in interactions $2,3,4$ and 6 .

An alternative to conventional economic theory is provided by behavioral economics. Although neither theoretical nor experimental behavioral economics provides as specific a set of predictions as does conventional theory, they do supply observations that permit characterization of trusting and trustworthiness. These may be listed as: (a) people often display trust and trustworthiness in real-life interactions resembling trust games, and large numbers have done so as well in past experimental trust games; ${ }^{13}$ (b) communication is helpful in engendering cooperation (as discussed above); (c) reciprocity is often observed (that is, many people act as if obligated to return kindness to someone who acts in a kind or trusting fashion toward them) $;{ }^{14}$ (d) many people have a preference for keeping their word; ${ }^{15}$ (e) there exist individual differences that generate a distribution of types in terms of money-maximizing versus other preferences; ${ }^{16}$ and (f) individuals choose their actions to maximize their utility (inclusive of any non-money

\footnotetext{
${ }^{11}$ The structure of the game with a binding contract is similar to the ultimatum game, with $A$ having the power to make a take-it-or-leave proposal.

${ }^{12}$ From a behavioral standpoint, the need to select first a contract and then to select penalties is a potentially problematic part of our design, because subjects desiring a contract with penalties might fear being stuck paying for a (useless, under the conventional economic assumptions) contract without penalties if their partner doesn't agree to having penalties, in the next step of the process (see again the detailed description of the procedure under Single Proposal, above). This is not problematic under the complete self-interest, rationality, and common knowledge of preferences assumptions, since no subject in either role $A$ or $B$ would reject penalties once "at least contract-without-penalties" had been chosen. With the cases in which these assumptions may not hold in mind, nevertheless, we checked the possible impact of the procedure by simplifying the options to either selecting no contract or selecting a contract with penalties, only, in sessions not reported here. The frequency of choosing contracts was not substantially different. We used the two-step process in our design because we wanted to study the effects of both kinds of contract, and because it would be problematic to have subjects simultaneously rank three options (in this case no contract, contract without penalties, contract with penalties).

${ }^{13}$ See again Journal of Economic Behavior and Organization, vol. 55, no. 4, 2004.

${ }^{14}$ References to the literature on reciprocity include Hoffman, McCabe and Smith (1998), Fehr and Gächter, (2000b), Ben-Ner and Putterman (2000) and Gintis, Bowles, Boyd and Fehr (2005), among many other contributions.

${ }^{15}$ Gneezy (2005), Sánchez-Pagés and Vorsatz (2004), Charness and Dufwenberg (forthcoming).

${ }^{16}$ Kurzban and Houser (2001), Fehr, Gächter and Fischbacher (2001), Page, Putterman and Unel (2005).
} 
preferences) subject to beliefs about partners' types, which may be influenced by information about partner characteristics or past actions. Based on these observations, we expect that:

- as in past trust game experiments, there will be considerable amounts of sending and returning even in interactions without pre-play communication;

- the amounts sent and returned will be greater the greater the amount of communication between partners, not only because of the way in which this aids coordination, signaling and screening of types, but also because with text messages especially, individuals can sometimes build a sense of trust in and responsibility toward their partners, and because the exchange of promises will make many feel bound to keep their word;

- trustors $(A)$ will send more when trustees $(B)$ have concurred on a proposal, because they will interpret this as an agreement to which $B$ may feel some degree of commitment;

- subjects will show special interest in proposals that achieve both efficiency and equity, i.e., $A$ sends $E \$ 10$ and $B$ returns $2 / 3$ of the amount received (or $\left(\mathrm{X}_{\mathrm{a}}, \mathrm{X}_{\mathrm{b}}\right)=$ $(E \$ 10, E \$ 20))$ for payoffs $(E \$ 20, E \$ 20)$;

- $\quad$ rather than make the $\mathrm{X}_{\mathrm{a}}=E \$ 10, \mathrm{X}_{\mathrm{b}}=E \$ 25$ proposal predicted by standard economics, even payoff-maximizing trustors $(A)$ are accordingly likely to suggest a more fair proposal, to increase the likelihood of their (possibly "fair minded") counterpart agreeing;

- payoff-maximizing trustors may forego contracts altogether when they attach a high probability to their counterpart returning the indicated amount, whether out of reciprocity or commitment, or they may prefer a less expensive contractwithout-penalties, if they believe it can compel sufficient commitment from their partner;

- when the partner's history of actions in previous interactions is provided (interaction 6), subjects in role $A$ will send more to partners who have returned more and have not violated contracts in their past interactions, and subjects in role $B$ will return more to partners who have sent more and have not violated contracts in their past interactions; 
The hypotheses generated by standard and behavioral economics thus disagree on most predictions. Whereas standard theory predicts $\left(\mathrm{X}_{\mathrm{a}}, \mathrm{X}_{\mathrm{b}}\right)=(0,0)$ in interaction $1,\left(\mathrm{X}_{\mathrm{a}}, \mathrm{X}_{\mathrm{b}}\right)=$ $(E \$ 10, E \$ 15)$ in all other interactions, conduct of the latter interactions under binding contracts, and no effect of communication, behavioral reasoning predicts some positive sending and returning in interaction 1 , the presence of efficient and fair $(E \$ 10, E \$ 20)$ proposals and interactions, real effects of communication, and at least occasional decisions to forego available contracts.

\section{Results}

We analyze here the 102 simple interactions that took place without pre-play communication and the 391 interactions that took place with pre-play exchange of proposals and the possibility of entering contracts. ${ }^{17}$ Of the latter, only $5.9 \%$ of interactions took place under a contract with penalties - contrary to the prediction of the conventional model that $100 \%$ would $-9.0 \%$ occurred under a contract without penalties, $71.4 \%$ under an agreed proposal but no contract, and $13.8 \%$ with neither agreement nor contract. Contrary to the conventional model, only 9 out of 391 proposals were to send 10 and return 25 , and $5(56 \%)$ of these were rejected, whereas $80 \%$ of proposals were to send 10 and return 20 , and $96 \%$ of such proposals were accepted. ${ }^{18}$ Average sending, returning, and earnings of trustors and trustees are summarized by interaction type in Table 1, and (for interactions 2, 3 and 4) by agreement or contract status in Table 2.

We discuss here some of the main results of our experiment in the form of a series of questions and answers.

\section{Q1. Is there trusting?}

We break this question into four parts, corresponding to our four interaction modes:

\footnotetext{
${ }^{17}$ The number of subjects interacting differs slightly from interaction to interaction (round to round) due to the accidental termination of some subjects' computer link-ups before their sessions were completed.

18 There were 3 proposals to send 10 and return 30, of which two were accepted, without resulting in a contract.
} 
Q1a. Do trustors send positive amounts in the simple interaction, where there is no preplay communication?

Yes. In the first simple trust interaction, $94 \%$ of subjects in role $A$ sent a positive amount (virtually identical to BDM's subjects), and 24.5\% exhibited high trust by sending all ten dollars of their endowment to subjects in role $B$ (compared to $15.6 \%$ in BDM). This strongly contradicts the prediction of the conventional model.

\section{Q1b. Do trustors place trust upon the implicit agreements of their counterparts?}

The data suggest that trustors do give at least some credence to their counterparts' concurrence on a proposal. Looking at interactions 2, 3 and 4, we find that trustors are significantly more likely to send the amount that they had proposed to send when their counterpart agreed with the proposal. ${ }^{19}$ In interaction 2 (one proposal, no chat), $87 \%$ of $A$ 's adhered to their proposal when $B$ concurred on it versus $35 \%$ when $B$ did not concur. In interaction 3 (multiple proposals, no chat) the corresponding numbers are $76 \%$ and $50 \%$, and in interaction 4 (proposals with chat) they are $95 \%$ and $75 \% .{ }^{20}$ The issue is also addressed simultaneously with the effects of interaction type and other controls in a GLS regression with subject fixed effects: column 1 of Table 3. Multiple proposal interactions and interactions with chat are controlled for by dummy variables, and since the terms proposed by $A$ may affect both the likelihood of $B$ agreeing and the amount that $A$ actually sends, these are also entered as controls. The estimate indicates that $A$ 's sent more to their counterparts when they agreed on the same proposal, significant at the $1 \%$ level. ${ }^{21}$ The first regression in Table 4 is identical except for dropping interactions

\footnotetext{
${ }^{19}$ We leave interaction 6 out of much of our analysis because once the possibility of reputation is introduced, as it is in that interaction, incentives to be trustworthy may be altered by reputational concerns.

${ }^{20}$ The first and third of these differences are significant according to Mann-Whitney tests at the $1 \%$ and $5 \%$ levels respectively; the difference in $A$ 's adherence to the proposal when $B$ concurred versus when $B$ did not concur is not significant in interaction 3 .

${ }^{21} \mathrm{We}$ also performed three checks of the robustness of this finding. First, because some of the additional sending might be due to the fact that those reaching agreement include a small number with binding contracts, we re-estimated the regression excluding the cases with binding and non-binding contracts. The results are shown in Table 4, and are not qualitatively different. Second, since an $A$ 's sending is bounded below at 0 and above at 10 , we used a tobit specification to estimate the regression. Coefficient signs and significance levels are qualitatively similar, but the $\chi^{2}$ of this regression as a whole is low, presumably because error terms are not normally distributed, related to the fact that more than $75 \%$ of $A$ 's in interactions 2 and 3 and more than $92 \%$ of $A$ 's in interaction 4 sent the full $E \$ 10$. Finally, we estimated a tobit regression using the smaller set of observations that excludes ones under contracts, as in Table 4; again, the results are similar.
} 
conducted under either kind of contract. It confirms that the positive effect of agreement on $A$ 's sending is not due to the assurance provided by contracts.

Q1c. Do trustors place trust in the contractual promises of their counterparts when these are not backed by penalties?

Subjects do show trust under a contract without penalties, but no more than do subjects operating under an agreement without contract. The proportion of those $A$ 's having a contract-without-penalties who sent the amount proposed is $90.9 \%$ in interaction $2,84.6 \%$ in interaction 3 and $75 \%$ in interaction 4 . In no case are the differences with the proportion of $A$ 's that fulfilled their part in agreements without contracts in the same interactions statistically significant.

It should be noted, however, that individuals who requested contracts are not a random group, and quite possibly those operating under a contract-without-penalties would have sent less had they operated without a contract. Comparing sending in the agreement-but-no-contract category by $A$ 's who did not ask for a contract versus $A$ 's who asked for but did not get a contract, we find that the latter sent significantly less.

\section{Q1d. Do trustors place trust in promises backed by penalties?}

In $100 \%$ of cases in which there was a contract with penalties, subject $A$ sent the amount agreed to. However, subjects in this situation could not gain monetarily by not sending what they promised, so there is no way to assess their degree of trust, per se.

\section{Q2. Is there trustworthiness?}

This, too, is broken into four parts.

Q2a. Do trustees return positive amounts in the simple interaction, where there is no preplay communication?

Yes. In the simple interaction, $80 \%$ of $B$ 's who were sent a positive amount returned something to the person with whom they were paired, with $74 \%$ returning at least as much as they were sent $\left(\mathrm{X}_{\mathrm{a}}\right)$ and $56 \%$ sending back more than $\mathrm{X}_{\mathrm{a}}$. Again, this strongly contradicts the prediction of conventional theory. 
Q2b. Do trustees return what they implicitly promised, when they have agreed on a proposal in pre-play communication?

For the most part, yes: $69.8 \%$ of trustees in interaction $2,67.2 \%$ in interaction 3 , and $87.1 \%$ in interaction 4 returned the amount indicated in the proposal they had agreed to. The somewhat lower adherence to proposals by $B$ 's than by $A$ 's seems unsurprising in view of the fact that $A$ 's stood to earn more by sending, assuming a high enough likelihood of trustworthiness by their partners, whereas each instance of adherence by a $B$ represented a monetary loss without possibility of compensation. What is surprising is that adherence to merely implied and entirely non-binding agreements was so high despite the inevitable lowering of earnings that it entailed.

Q2c. Do trustees return what they committed to return in a contract without penalties?

Again, mostly yes, but no more so than under agreements without contracts. The proportions fulfilling their parts of a contract-without-penalties when their counterpart sent the proposed amount are $85.7 \%$ in interaction 2, 64.3\% in interaction 3 and $66.7 \%$ in interaction 4 . In no case is the proportion statistically significantly different from the corresponding proportion of adherence by those operating under agreements without contracts.

Q2d. Do trustees return what they committed to return under a contract with penalties?

Yes. $100 \%$ of contracts with penalties are fulfilled by trustees (as with trustors, it was materially beneficial to fulfill the contract given the size of the penalties).

\section{Q3. Does trusting pay off in our experiment?}

We break this question into three parts.

Q3a. Do A's who send positive amounts earn more than those who send nothing?

Yes. Those who send 0 automatically earn 10 . In interaction 1 , the six subjects who sent 0 thus earned $E \$ 10$, and the ninety-six subjects who sent positive amounts earned an average of $E \$ 11.6$. This difference is statistically significant in a Mann- 
Whitney test but only at the $10 \%$ level and only in a one-tailed test. When we pool the observations from interactions 1, 2, 3 and 4 together, however, we have 25 cases of sending 0 (earning $E \$ 10$ ) and 371 cases of sending positive amounts, with average earnings of $E \$ 14.30$. This difference is significant at the $0.1 \%$ level.

Q3b. Are earnings by A's increasing in the amount that they send?

We study this question by estimating OLS regressions in which $A$ 's round earnings are the dependent variable and $A$ 's sending is the sole explanatory variable. When this regression is estimated for interaction 1 only, the coefficient on $A$ 's sending is a positive 0.23 , but not significant. When observations for interactions $1,2,3$ and 4 are pooled, the coefficient is a larger positive number, 0.70 , and is significant at the $0.1 \%$ level. On average, trusting paid off (despite standard theory's inference that $B$ 's will send nothing back, so that trusting necessarily reduces earnings).

Q3c. Do A's who follow through on an agreement earn more than those who do not?

Mann-Whitney tests show that $A$ 's who sent the agreed amount when there was an agreement without contract earned more than those who did not, significant at the $1 \%$ level in each of interactions 2, 3 and 4 . So being trustworthy in the sense of following through on an implicit agreement paid off for $A$ 's.

\section{Q4. Does trustworthiness pay off?}

This question is broken into two parts.

Q4a. Is there an immediate material payoff to being trustworthy?

In the context of our experiment, the answer is of course "no." The more subject $B$ returns to subject $A$, the less subject $B$ earns. For example, in interaction 1, the nineteen trustees who sent back 0 when sent a positive amount earned an average of $E \$ 30.8$, whereas the seventy-seven trustees who sent back positive amounts earned an average of E\$17.3. 
Q4b. Is there a material payoff to being trustworthy in interactions that allow for an impact of reputation?

Although our experiment was not designed to investigate the incentive effect of reputational considerations, ${ }^{22}$ we can ask whether subjects in role $B$ who had violated a contract in the past ${ }^{23}$ were punished in interaction 6 in the form of significantly less trusting by their counterparts, and whether that punishment was of sufficient magnitude so as to reduce the earnings of those subjects.

The data for the 97 interactions in round 6 show that the 11 subjects $B$ who were reported to have violated a contract in the past were sent an average of $E \$ 7.3$, whereas the 86 who had not violated a contract were sent an average of $E \$ 7.7$, a difference in the expected direction but far smaller than expected and statistically insignificant. Moreover, because the past contract violators continued to be of a less reciprocating type, their earnings in round 6 were actually higher than those of the non-violators: $E \$ 26.4$ for the violators versus $E \$ 19.8$ for the non-violators, a significant difference. ${ }^{24}$

\section{Q5. Does pre-play communication increase trusting and earnings of trustors?}

We break this into four parts.

Q5a. Does pre-play exchange of proposals increase sending by trustors?

Column 1 Table 5 reports a regression in which sending by $\mathrm{A}$ is the dependent variable and the explanatory variables are dummy variables for interactions 2, 3 and 4 and subject fixed effects, not shown. All 396 valid observations for interactions 1 through 4 are included. The positive and highly significant coefficients for interactions 2 and 3 suggest that pre-play exchange of one set of proposals raised average sending substantially over that in simple interactions, with the opportunity to send multiple

\footnotetext{
${ }^{22}$ Before interaction 6, it was never mentioned to subjects that their past actions might become known to future partners.

${ }^{23}$ Subjects learned of contract violation without differentiation as to type of contract, but were given no information about violation of agreements without contracts.

${ }^{24}$ See again Figure 3 for the form in which information on a partner's past behavior was presented to subject $A$. We think that the surprising result in $\mathrm{Q} 4 \mathrm{~b}$ should be treated with considerable caution since it is conceivable that the manner in which the information was presented was not salient enough to have been properly noticed by some subjects.
} 
proposals raising sending by somewhat more, consistent with the averages reported in the "A sends" column of Table $1 .{ }^{25}$

Q5b. Does pre-play exchange of verbal messages increase sending by trustors?

The fact that the coefficient on the interaction 4 dummy variable in column 1 of Table 3 is significant and substantially larger than the coefficients for the interaction 2 and 3 dummy variables is a clear indication that exchange of verbal messages increased sending over and above the increase due to exchange of numerical proposals alone. Table 4 confirms that the result doesn't depend on inclusion of interactions under contracts. These results are in line with the corresponding coefficients in Table 5 and with Table 1, which shows that sending in interaction 4 was on average more than a dollar greater than in interactions 2 and 3 and almost four dollars greater than in interaction 1.

Q5c. Does pre-play exchange of verbal messages increase the credibility of B's concurrence on a proposal, as indicated by an increase in adherence by trustors to their proposals?

There is evidence that this is so. $94.4 \%$ of A's send the agreed amount in interaction 4 when there is an agreement without contract as compared with $88.2 \%$ in interaction 2 .

Q5d. Does pre-play communication affect earnings of trustors?

Column 2 of Table 5 shows the result of a GLS regression with subject fixed effects, paralleling that of column 1 but replacing $A$ 's sending by $A$ 's payout. The estimated coefficients on interactions indicate that exchange of either single or multiple

\footnotetext{
${ }^{25}$ The fact that sending increases with each additional round raises the question of whether the results in the regression might be attributable to repetition rather than to the differing communication conditions. The design of the present experiment makes it difficult to rule this out, although significant effects of pre-play communication, and especially chat communication, remain if data for all seven rounds are included and the explanatory variables include round number and its square. As a better test, we separately conducted sessions in which five one-shot interactions identical to interaction 1 preceded five interactions with exchange of proposals or chat and exchange of proposals. While sending also increased over time in the first four of those interactions, the rate of increase is substantially smaller, significant at the $0.1 \%$ level in a one-tailed Mann-Whitney test.
} 
proposals affects significantly $A$ 's earnings, but that verbal communication increases $A$ 's earnings even more. ${ }^{26}$

\section{Q6. Does pre-play communication increase trustworthiness?}

We break this also into three parts.

Q6a. Does pre-play exchange of proposals increase amounts returned by trustees?

Column 3 of Table 5 shows the result of a GLS regression with subject fixed effects, where the interaction table (Fig. 1) column selected by $B$ is the dependent variable. The amount sent by $A$ is included as an explanatory variable, since it sets the budget constraint of what $B$ can potentially return. Interactions in which $A$ sent nothing are excluded, since they leave $B$ with no choice to make. Neither the coefficient for interaction 2 nor that for interaction 3 is statistically significant, so exchange of numerical proposals without verbal communication appears not to affect returning.

Q6b. Does pre-play exchange of verbal messages increase amounts returned by trustees?

Of the three interaction dummies in the column 3 regression, only that for interaction 4 has a significant (at 5\%) coefficient, which is positive, indicating that trustees sent substantially more back per dollar received from their counterparts in interactions allowing exchange of verbal messages. This result - a sacrifice of earnings to adhere to an agreement reached through words - supports the behavioral but not the conventional model.

Q6c. Does pre-play exchange of verbal messages increase adherence of trustees to their agreements?

The great majority, $88.1 \%$ of trustees, returned the proportion they agreed to in interaction 4 while $73.1 \%$ returned the agreed proportion in interaction 2 . The difference is significant at the 5\% level in a two-tailed Mann-Whitney test and at the $1 \%$ level in a one-tailed test. If we pool the observations of interactions 2 and 3, interactions allowing proposals but no chat, we find the difference in trustees' adherence to their agreements in

\footnotetext{
${ }^{26}$ See again the discussion of order affects in footnote 25.
} 
interactions with verbal communication versus those with only numerical proposals is even more significant. Verbal pre-play communication significantly increased trustees' trustworthiness, or in other words, their commitment to their agreements.

Q6d. Does pre-play communication affect earnings by trustees?

Column 4 of Table 5 shows a GLS regression with subject fixed effects in which trustee earnings is the dependent variable. The estimated coefficients on the interaction dummies are all negative, indicating lower earnings by trustees in interactions with preplay communication than in those without such communication, significant at the $10 \%$ level for interaction 2 and at the $1 \%$ level for interaction 4 . Although communication led to greater trusting by $A$ 's, once that sending is controlled for, the additional effect of communication on earnings of $B$ 's is a negative one since it led them to be more reciprocating toward their counterparts.

\section{Q7. Do some forms of communication increase the likelihood of reaching an agreement?}

Yes. The proportion of interactions that led to an agreement was $91.8 \%$ for interactions with chat, higher than the $78 \%$ to $82 \%$ for interactions with proposals but no chat. Agreements were reached in an even larger percentage of cases, $94 \%$, in interactions allowing multiple proposals. To test the effect formally, we estimated a probit regression (not shown) in which the dependent variable is 1 if an agreement was reached and 0 otherwise, and explanatory variables are subject fixed effects and dummies for interactions 3 and 4 (the observations are for interactions 2, 3 and 4 only). The interaction 3 and interaction 4 dummies are both highly significant $(0.1 \%$ level $)$ and positive, but not significantly different from each other $\left(\chi^{2}(1)=0.62\right)$. Hence, additional opportunities to communicate-whether by iterating on numerical proposals or verbally - increased the likelihood of reaching agreements to about the same degree.

\section{Q8. Do agreements and contracts increase trusting and payoffs to trustors?}

We ask separately: 
Q8a. Do agreements without contracts increase trustors' sending?

Table 2 lists the average behaviors and earnings of trustors and trustees in interactions 2, 3 and 4, sorted by whether an interaction took place under a contract with penalties, a contract without penalties, an agreement without contract, or neither agreement nor contract. The first column shows that trustors whose partner agreed with them on a proposal but who operated without a contract sent an average of $E \$ 8.83$, whereas those who did not achieve agreement sent only $E \$ 4.70$. Further evidence is provided by the regression in Column 1 of Table 3, where the fact that $B$ 's agreement might be endogenous to the terms proposed by $A$ is controlled by inclusion of those terms. The large and highly significant coefficient on agreement supports the conclusion that agreement increased sending. More importantly, the corresponding regression in Table 4 drops interactions in which the subjects subsequently decided to use a contract, yet confirms largely the same effect of operating with agreement.

\section{Q8b. Do agreements without contracts increase trustors' payoffs?}

Table 2 shows that earnings of trustors interacting without agreements averaged $E \$ 10.11$, whereas those with agreements earned an average of $E \$ 15.39$ per round. In column 2 of Table 3 , which is identical to column 1 but with $A$ 's round earnings (including deduction of any contract costs) rather than sending as dependent variable, the coefficient on agreement by $B$ is also large and significant, indicating that trustors not only trusted more but also earned more when there was acceptance of their proposal. The corresponding column of Table 4 confirms that this result doesn't depend on the inclusion of interactions that resulted in contracts.

Q8c. Do contracts without penalties increase trustors' sending and payoffs?

Our evidence suggests that there was actually less, not more, trusting by $A$ 's operating under contracts without penalties. Table 2 shows that trustors who entered into a contract without penalties sent on average less $(E \$ 8.11)$ than trustors who reached agreement but did not go on to enter a contract ( $E \$ 8.83)$. Another indication of reduced trust, not shown in the table, is that trustors sent at least as much as they had proposed in $76.9 \%$ of interactions involving a contract without penalties, versus in $87.3 \%$ of 
interactions involving an agreement but no contract. Trustors also earned significantly less on average with contracts without penalties than without contracts $(E \$ 12.66$ versus $E \$ 15.39$ in column 3 of Table 2, significant at the $0.1 \%$ level in a Mann-Whitney test). ${ }^{27}$ It seems that those who entered a contract without penalties may on average have been somewhat less trusting than those who operated with an agreement but no contract. ${ }^{28}$ However, the first column regression in Table 6 fails to corroborate the idea that subjects were less trusting under contracts without penalties, once subject fixed effects and the interaction are controlled. This regression includes only those observations from interactions 2, 3 and 4 in which agreements were reached, studying the additional effect, if any, of entering into one or the other type of contract, while including $A$ 's proposal terms, which might influence both actual sending and returning choices and decisions on whether to enter contracts.

Might the particular subjects who ended up with contracts without penalties have been even less trusting when forced to operate without a contract? One way to investigate whether those trustors who asked for a contract were on average less trusting is to look at the set of $A$ 's who operated without a contract, which includes some who didn't request a contract and some who requested but were denied a contract. Consistent with the conjecture, we find that $A$ 's who asked for but were denied a contract of any kind (due to their counterpart not asking for a contract) sent an average of $E \$ 8.2$, while those $A$ 's who did not request a contract sent an average of $E \$ 9.1$, a difference significant at the $1 \%$ level. Further evidence comes from looking at those operating under a contract-without-

\footnotetext{
${ }^{27} A$ 's also earned less under contracts without penalties (an average of $E \$ 14.1$ ) when the contract cost itself is not considered.

${ }^{28}$ Note that those operating under agreements without contracts also included many who would have preferred a contract. Under our experimental design, no contract arose unless both of the parties who had been matched for the exchange agreed on a proposal and chose to have a contract. $A$ 's asked for at least a contract without penalties $52.5 \%$ of the time, but $B$ 's asked for at least a contract without penalties only $37.3 \%$ of the time, and $A$ 's who wanted a contract got one on $30.1 \%$ of their requests, while $B$ 's did on $41.8 \%$ of their requests. Since those operating without a contract included also all those who reached agreement and didn't want a contract, the group operating with a contract could be biased in favor of less trusting individuals. Also, of those operating under a contract without penalties, $60.7 \%$ of the $A$ 's and $10.7 \%$ of the $B$ 's would have preferred a contract with penalties; that is, they went on to request a contract with penalties, but did not get it because their counterpart did not request one. In all, $80 \%$ of $A$ 's who requested and got a contract without penalties went on to request that penalties be added to the contract, which implies that only $20 \%$ saw a contract without penalties as worthwhile in its own right. Since it is mainly $A$ 's who were not trusting enough to forego a costly contract with penalties that ended up in contracts without penalties, their lower average trust compared to the agreement-without-contract group, containing a substantial number of $A$ 's trusting enough to forego a contract entirely, is not surprising.
} 
penalties. We find that lack of trusting, manifested by sending less than agreed to, occurs only among $A$ 's who wanted a contract with penalties but failed to get one (because their counterpart didn't want one). Among trustors acting under a contract without penalties, $36 \%$ (9 out of 25 ) of those who wanted but did not get a contract with penalties sent less than the amount agreed to, whereas none of the 14 who did not want a contract with penalties sent less than agreed to.

Turning to earnings, column 3 of Table 2 shows that on average, trustors interacting under contracts without penalties earned nearly $E \$ 3$ less than those operating with an agreement but no contract (the contract cost accounts for some of the difference). But according to the second regression in Table 6, the difference is insignificant, and (perhaps due to the other controls) the coefficient is in fact positive.

Q8d. Do contracts with penalties increase trustor sending and/or earnings?

Table 2 shows that trustor sending was highest under contracts with penaltiesclose to the efficient level of $E \$ 10$, while trustor earnings were also higher than in other conditions, close to $E \$ 17$, which means more or less the fair and efficient outcome for $A$ (see below) minus the contract cost. So insofar as their goal was to maximize their expected return, those $A$ 's who requested a contract in the hope of getting a contract with penalties can be deemed (ex post) rational.

\section{Q9. Do agreements and contracts increase trustworthiness and payoffs of trustees?}

We ask separately:

Q9a. Do agreements without contracts increase the proportion of the money received that trustees' returned?

Table 2 shows that trustees who agreed on a proposal with their counterpart returned an average of $53 \%$ of what they received, whereas those who did not reach an agreement returned an average of $32 \%$. Since trustor sending also varied depending on whether agreement was reached, the amount returned by the trustee differs more substantially: $E \$ 15.06$ with agreement versus $E \$ 5.76$ without. Returning to the regressions of Table 4, using observations from those interactions 2, 3 and 4 that were 
conducted without contracts, column 3's regression indicates that having an agreement increased $B$ 's column choice by almost a full column, significant at the $5 \%$ level.

Clicking on the same row and column as $A$ had done led $B$ to return more-possibly as a result of a sense of commitment to the agreement on $B$ 's part. (Recall again that $B$ 's onscreen instructions explicitly stated that $B$ was free to choose something other than the column she or he had previously highlighted.)

\section{Q9b. Do agreements without contracts increase trustees' earnings?}

In the last column of Table 4, we show the estimate of a regression identical to that reported in Q9a except that the dependent variable is $B$ 's round earnings (including deduction of any contract cost). The coefficient on $B$ agreeing is this time a negative 3.45 , significant at the $10 \%$ level. The presence of a weak tendency for $B$ to earn less makes sense given that $B$ must earn less the more $B$ returns, holding all else equal. That the effect is not very significant reflects the off-setting tendency for $A$ to send more to $B$ when there is an agreement. Indeed, Table 2 shows that $B$ 's average earnings are higher with an agreement than without.

\section{Q9c. Do contracts without penalties increase trustees' payoffs?}

Columns 4 and 5 of Table 2 show that on average trustees operating under contracts without penalties sent a slightly smaller share of their receipts back to their trustors than those with agreements but not contracts, with the absolute amount returned having a larger gap because of the difference in trustor sending. The regression in the third column of Table 6 , however, suggests that after controlling for $A$ 's sending, $A$ 's proposal terms, the type of interaction, and subject fixed effects, there is a positive but insignificant effect of a contract without penalties on the amount returned by trustees. Nevertheless, the regression in column 4 indicates that having a contract without penalties had a negative effect on $B$ 's earnings that is significant at the $10 \%$ level. $B$ 's earnings are also shown to be a little less on average under contracts without penalties than under agreements, in Table $2 .^{29}$

\footnotetext{
${ }^{29}$ The latter difference is significant at the $1 \%$ level in a two-tailed Mann-Whitney test. An interesting point is that it is largely the greater voluntary compliance of subjects in the $B$ role with their agreements
} 
Q9d. Do contracts with penalties increase trustees' payoffs?

No. Table 2 shows that trustees earned an average of $E \$ 16.39$ (after contract costs) under a contract with penalties, less than average earnings in each of the other three contractual and agreement statuses. In fact, the table shows that B's earned the most on average under agreements without contracts, less under contracts without penalties, and less still under contracts with penalties - a finding that may help to explain the greater reluctance of B's than of A's to enter into contracts, especially those with penalties (also see again the answer to Q8d).

\section{Q10. Are trusting and trustworthiness enhanced by proposals and agreements that are "fair and efficient?"}

We call an interaction or proposal "fair and efficient" if it involves the pair of actions $\left(\mathrm{X}_{\mathrm{a}}, \mathrm{X}_{\mathrm{b}}\right)=(E \$ 10, E \$ 20)$, since this leads to the most equal division of the largest sum of earnings. An interesting finding in our data is that in exchanges in which proposals were possible, $A$ 's first proposal was fair and efficient $80.5 \%$ of the time, and such proposals were agreed to by $B 96.2 \%$ of the times when they were made, versus $53.3 \%$ of the time on average for other proposals. The difference is significant at the $0.1 \%$ level in a two-tailed Mann-Whitney test. ${ }^{30}$ Both $A$ 's and $B$ 's were more likely to implement a fair and efficient proposal as opposed to other proposals, once agreed on. Agreements were carried out by both $A$ and $B 64.6 \%$ of the time when they were fair and efficient, versus $32.7 \%$ of the time when not. This contrasts sharply with the conventional theory's prediction that $A$ would propose and $B$ agree to $\left(\mathrm{X}_{\mathrm{a}}, \mathrm{X}_{\mathrm{b}}\right)=(E \$ 10, E \$ 25)$, the proposal that maximizes $A$ 's earnings subject to giving $B$ a positive gain from trade.

\footnotetext{
that makes contracts-without-penalty costly to them. A plausible interpretation, then, is that some $B$ 's chose not to enter a contract-without-penalties because they anticipated that they would then feel (honor) bound by it, whereas they might feel more freedom to deviate after simply clicking a row and column without any explicit expression of commitment.

${ }^{30}$ Differences are likewise significant at the $0.1 \%$ level for interactions 2,3 and 4 taken individually. In interaction 3 , we treat $B$ as accepting the $(20,20)$ proposal if $B$ accepts it at any of the first, second, or third possible rounds of proposals. The acceptance rate of $(20,20)$ proposals in interaction 3 is $100 \%$ (versus $54.6 \%$ for other proposals made in that interaction).
} 


\section{Q11. Does presentation of possible actions and results in the Figure 1 decision grid, and use of that grid to conduct the interactions, have a framing effect?}

Apparently yes. By displaying to subjects the final division of earnings associated with each sending and returning choice, the grid makes clear that an equal division of the largest possible pie requires $B$ to return not half (a cognitive error likely to be reinforced by unconscious self-interested bias, had the information not been displayed) but two thirds of the money received from A. The $(20,20)$ earnings outcome is reached in $10.4 \%$ of our interactions without communication, $50.7 \%$ of our interactions with proposals but no chat, and $78.3 \%$ of our interactions with both chat and proposals. Contrast BDM, most directly comparable to our interaction 1 , in which only one in thirty-two interactions (3.1\%) ended in the $(20,20)$ split (one in twenty-eight-3.6\% - in their history treatment). ${ }^{31}$ The frequency of $(20,20)$ proposals in our experiment is also prima facie evidence of a framing effect.

\section{Conclusions}

We conducted series of one-shot trust interactions with anonymous partners in some of which subjects sent non-binding pre-play proposals and counterproposals, sometimes with prior exchange of chat messages. Pre-play communication was accompanied by the opportunity to enter either a binding or a non-binding formal contract if agreement was reached on a course of action. One of the interactions which we discussed briefly also gave subjects partner history information.

Our analysis of subject choices led to a number of significant findings. We find that both trusting and trustworthiness were significantly increased by opportunities to exchange proposals and counterproposals, and further increased when verbal messages could also be sent. Most agreements reached by the simple exchange of proposals were adhered to, with a still higher rate of follow-through when the subjects had also "chatted" and/or when the agreement had the characteristic of being efficient and fair. Trust "paid off" under all conditions in our experiment, with more trusting seeming to engender more trustworthiness. The modal agreement was to the most equitable of the efficient sets of

\footnotetext{
${ }^{31}$ Two of the five trustors who sent 10 in BDM's no-history condition (three of seven, in their history treatment) received back 15 , or half of what $B$ received - far higher proportions than in our data.
} 
actions, and such agreements were carried out by both parties significantly more often than were other agreements.

We provided the first laboratory illustration of the familiar proposition that the presence of trust can save on transactions costs: a great deal of mutually profitable trusting and trustworthiness took place without contracts even though the alternative of costly contracts was available, and many individuals were able to commit themselvescredibly, in the eyes of their partners - to courses of action that were not ex post materially profitable, contrary to the assumption of standard theory.

The large majority of instances of trusting and trustworthiness in those interactions in which contracts could be opted for took place without contracts. Out of all interactions in our experiment in which agreements and contracts were possible, agreements (concurrence on the same proposal by $A$ and $B$ ) occurred in $84.3 \%$ of cases, contracts without penalties were adopted in $6.7 \%$ of cases, and contracts with penalties were adopted in $5.3 \%$ of cases. Of the cases in which $A$ exhibited trust by sending a positive amount to $B$, only $6.4 \%$ were interactions in which a contract without penalties had been adopted, $5.8 \%$ ones in which a contract with penalties was in force. The fact that the large majority of sending took place without a binding contract, even though such a contract was available and led to the highest outcome considered feasible under the assumptions of conventional economic theory, is noteworthy.

We also found that explicit statement of payoffs to parties appears to increase sharply the incidence of fair and efficient outcomes. If this result can be validated by other experiments, especially those carried out with direct comparative treatments, then it would constitute further support for the value of transparency in economic transactions, as well as further proof that the earnings applications of actions cannot be assumed to be understood by experimental subjects merely because mathematically adequate information has been announced to them.

Our findings resemble Malhotra and Mulligan's in that agreement to proposed cooperation by $B$ 's (who in their case initiated the proposal and whose role was assumed by the computer) led to significantly increased trusting by $A$ 's. They also resemble Charness and Dufwenberg's finding that $B$ 's tend to be trustworthy after "giving their word"- a result which those authors attribute to wanting to live up to their counterparts' 
expectations. But ours is the first such experiment with real players on both sides able to exchange not only proposals but also verbal messages, and having the option to enter into binding contracts.

Like those of many other experiments, our findings suggest that major revisions are required in economic theory for it to be predictive of behavior in situations where cooperation and trust might play important roles. Although the amounts of money at stake were somewhat modest, it must be emphasized that the vast majority of our subjects went to the trouble of reporting to the lab mainly because they were interested in earning some extra money, as their chat room statements frequently attest. Each time a trustee sent $E \$ 20$ to her counterpart, rather than keep it, she was giving up a real $\$ 2.80$ in potential take-home earnings. That so many refrained from behaving opportunistically towards anonymous partners is a strong indication of the impact of social norms on interactions of the kind that make up so much of the everyday life of organizations. And the observed powerful effects of communication suggest that the more "real" those whom an individual interacts with become to him or her, the more likely it is that these norms will be triggered. 


\section{References}

Ben-Ner, Avner and Louis Putterman, 2000, "On Some Implications of Evolutionary Psychology for the Study of Preferences and Institutions," Journal of Economic Behavior and Organization 43: 91-99, 2000.

Ben-Ner, Avner and Louis Putterman, 2001, "Trusting and Trustworthiness," Boston University Law Review 81 (3): 523-551.

Ben-Ner, Avner and Louis Putterman, in progress, "Does Communication Aid Trust? An Experiment," unpublished paper, Brown University and University of Minnesota.

Ben-Ner, Avner, Brian McCall, Massoud Stephane, and Hua Wang, 2006, "Identity and Self-Other Differentiation in Work and Giving Behaviors: Experimental Evidence," unpublished paper, University of Minnesota.

Berg, J., John Dickhaut, and Kevin McCabe, 1995, "Trust, Reciprocity and Social History," Games and Economic Behavior 10: 122-42.

Bochet, Olivier, Talbot Page and Louis Putterman, 2006, "Communication and Punishment in Voluntary Contribution Experiments," Journal of Economic Behavior and Organization 60: 11-26.

Bochet, Olivier and Louis Putterman, 2005, "Not Just Babble: A Voluntary Contribution Experiment with Iterative Numerical Messages," Department of Economics Working Paper 2005-05, Brown University.

Bohnet, Iris, Richard Zeckhauser, 2004, “Trust, Risk and Betrayal," Journal of Economic Behavior and Organization 55 (4): 467-84.

Briggs, Stephen R., 1992, "Assessing the Five-Factor Model of Personality Description," Journal of Personality 60: 253-93.

Brosig, Jeannette, 2002, "Identifying Cooperative Behavior: Some Experimental Results in a Prisoner's Dilemma Game," Journal of Economic Behavior and Organization 47: $275-90$.

Brosig, J., Ockenfels, A., Weimann, J., 2003, "The effect of communication media on cooperation," German Economic Review 4, 217-42.

Buchan, N., Croson, R., Johnson, E., 2006, “Let's get personal: An international examination of the influence of communication, culture and social distance on other regarding preferences," Journal of Economic Behavior and Organization 60: 373-98. 
Carpenter, Jeffrey, 2003, "Bargaining Outcomes as the Result of Coordinated Expectations: An Experimental Study of Sequential Bargaining," Journal of Conflict Resolution 47(2): 1190139.

Charness, Gary and Martin Dufwenberg, forthcoming, "Promises and Partnerships," Econometrica.

Christie, Richard and Florence Geiss, 1970, Studies in Machiavellianism, New York: Academic Press.

Cox, James, 2004, "How to identify trust and reciprocity," Games and Economic Behavior 46: 260-81.

Eckel, Catherine and Rick Wilson, 2004, "Is Trust a Risky Decision?” Journal of Economic Behavior and Organization 55 (4): 447-65.

Fehr, Ernst and Simon Gächter, 2000, "Cooperation and Punishment," American Economic Review 90: 980-94.

Fehr, Ernst and Simon Gächter, 2000b, "Fairness and Retaliation: The Economics of Reciprocity," Journal of Economic Perspectives 14 (3): 159-81.

Fehr, Ernst, Simon Gächter and Urs Fischbacher, 2001, “Are People Conditionally Cooperative? Evidence from a Public Goods Experiment," Economics Letters 71 (3): 397-404.

Fehr, E. and Bettina Rockenbach, 2003, "Detrimental Effects of Sanctions on Human Altruism," Nature 422: 137-40.

Frohlich, Norman and Joe Oppenheimer, 1998, "Some Consequences of e-mail vs. Faceto-Face Communication in Experiment," Journal of Economic Behavior and Organization 35 (3): 389-403.

Gintis, Herbert, Samuel Bowles, Robert Boyd and Ernst Fehr, eds., 2005, Moral Sentiments and Material Interests: The Foundations of Cooperation in Economic Life. Cambridge, MA: MIT Press.

Gneezy, Uri, 2005, "Deception: The Role of Consequences," American Economic Review 95(1): 384-294.

Hoffman, Elizabeth, Kevin McCabe and Vernon Smith, 1998, "Behavioral Foundations of Reciprocity: Experimental Economics and Evolutionary Psychology," Economic Inquiry 36: 335-52. 
Houser, Daniel, Erte Xiao, Kevin McCabe and Vernon Smith, "When Punishment Fails: Research on Sanctions, Intentions and Non-Cooperation," unpublished paper, George Mason University.

Isaac, R. Mark and James M. Walker, 1988, "Communication and Free-Riding Behavior: The Voluntary Contributions Mechanism,” Economic Inquiry 26: 585-608.

James, Harvey S., 2002, "The trust paradox: a survey of economic inquiries into the nature of trust and trustworthiness," Journal of Economic Behavior and Organization 47: 291-307.

Kurzban, Robert and Daniel Houser, 2001, "Individual Differences in Cooperation in a Circular Public Goods Game,” European Journal of Personality 15 (S1): S37-S52.

McCabe, Kevin, Mary Rigdon and Vernon Smith, 2003, "Positive Reciprocity and Intentions in Trust Games," Journal of Economic Behavior and Organization 52: 267-75.

Malhotra, Deepak and J. Keith Murnighan, 2002, “The Effects of Contracts on Interpersonal Trust," Administrative Science Quarterly 47:534-559.

Ochs, Jack and Alvin E. Roth, 1989, “An Experimental Study of Sequential Bargaining," American Economic Review 79(3): 355:385.

Oosterbeek, Hessel, Joep Sonnemans, and Susan van Velzen, 2004, "Specific Investments, Holdup, and the Outside Option Principle," European Economic Review 48: 1399-1410.

Ostrom, Elinor, James Walker and Roy Gardner, 1992, "Covenants with and without a Sword: Self Governance is Possible." American Political Science Review. 86 (2): 404416.

Page, Talbot, Louis Putterman and Bulent Unel, 2005, "Voluntary Association in Public Goods Experiments: Reciprocity, Mimicry, and Efficiency," Economic Journal 115: 1032-53.

Rigdon, Mary, 2005, “Trust and Reciprocity in Incentive Contracting," U. of Michigan, 2005.

Rubinstein, Ariel, 1982, "Perfect Equilibrium in a Bargaining Model," Econometrica 50(1): 97-109.

Rubinstein, Ariel, 1985, “A Bargaining Model with Incomplete Information about Time Preferences," Econometrica 53(5):1151-72.

Sally, David, 1995, "Conversation and Cooperation in Social Dilemmas: A MetaAnalysis of Experiments from 1958 to 1992," Rationality and Society 7 (1): 58-92. 
Sánchez-Pagés, Santiago and Marc Vorsatz, "An Experimental Study of Truth-Telling in a Sender-Receiver Game,” Discussion Paper, Edinburgh School of Economics, 2004.

Wilson, Rick and Jane Sell, 1997, “'Liar, Liar...': Cheap Talk and Reputation in Repeated Public Goods Settings," Journal of Conflict Resolution 41 (5): 695-717. 


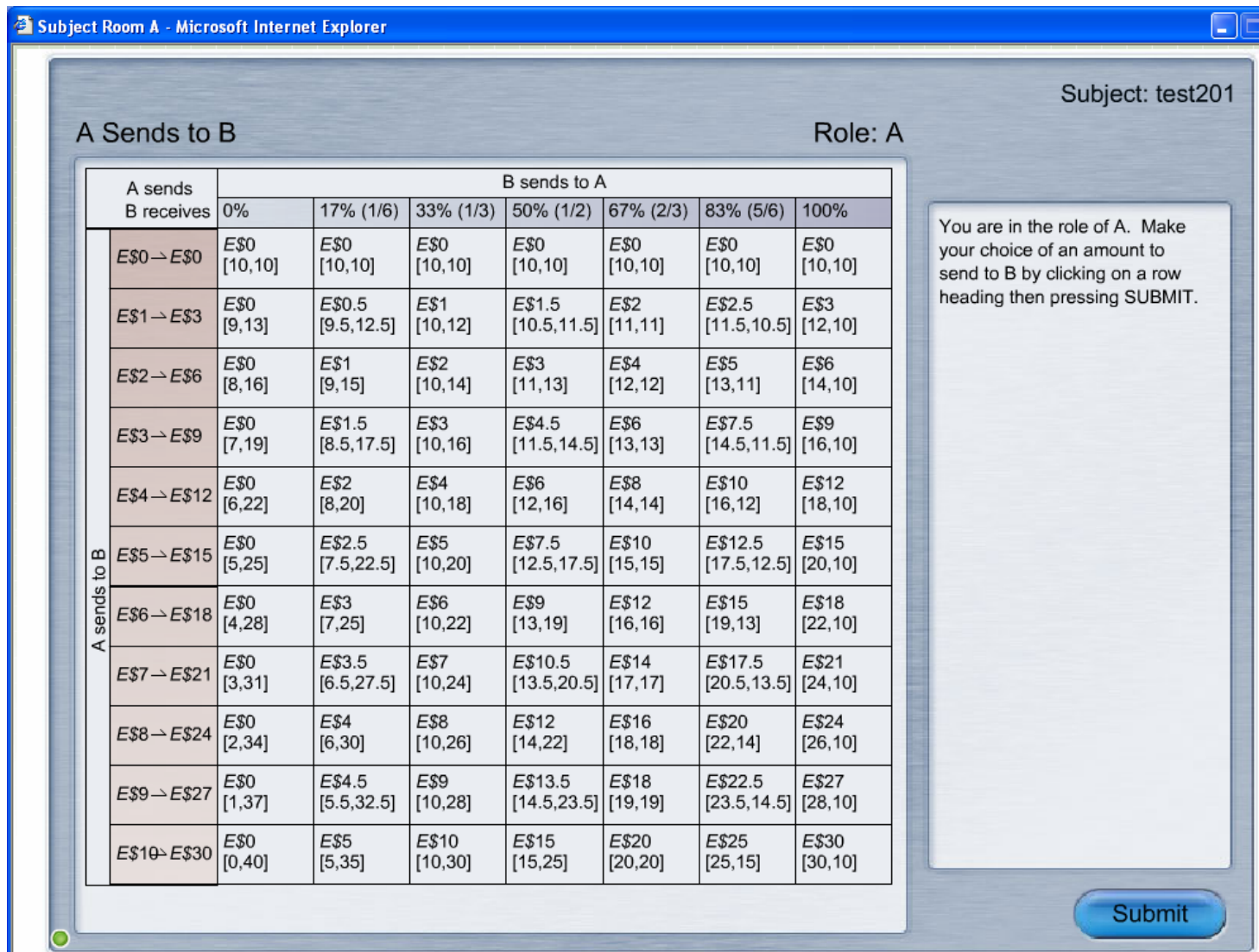

Figure 1. Interaction table 


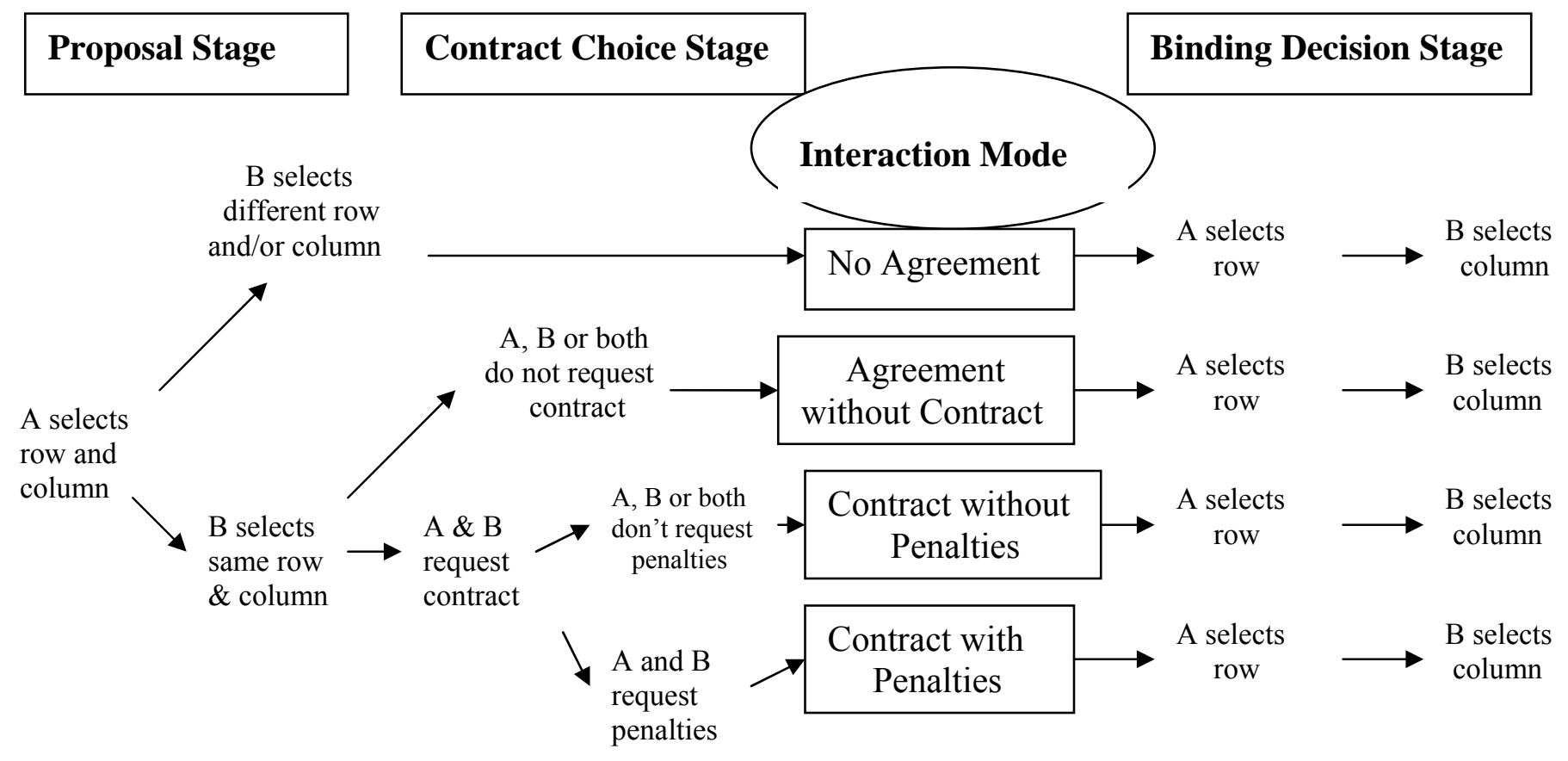

Figure 2. Decision sequence for single proposal interaction 


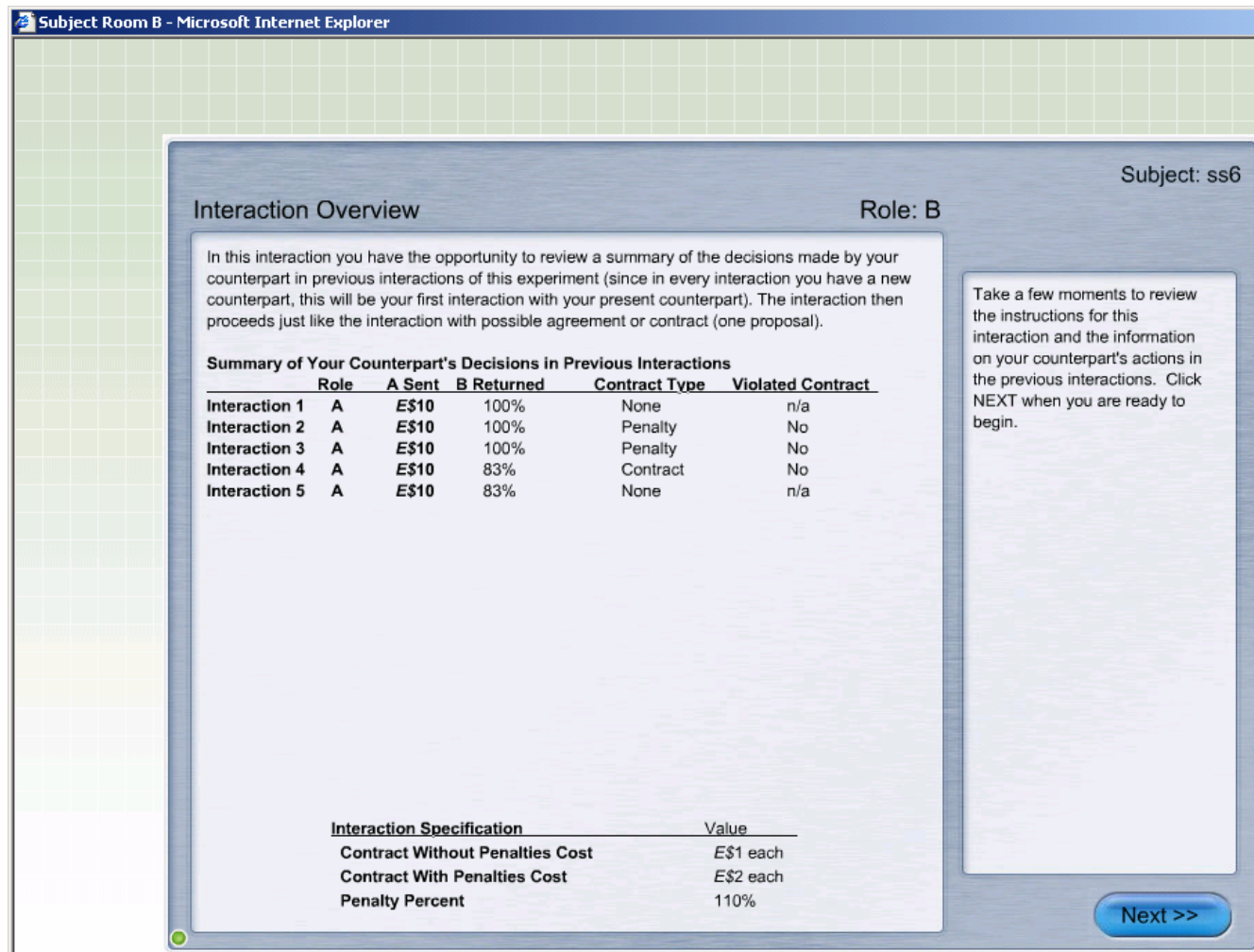

$\begin{array}{ll}\text { Contract Without Penalties Cost } & E \$ 1 \text { each } \\ \text { Contract With Penalties Cost } & E \$ 2 \text { each } \\ \text { Penalty Percent } & 110 \%\end{array}$

Figure 3. History information screen for counterpart history and single proposal interaction (interaction 6) 
Table 1. Average outcomes by interaction

\begin{tabular}{|c|c|c|c|c|c|}
\hline \multirow{2}{*}{$\begin{array}{c}\text { Interaction } \\
\text { Type }\end{array}$} & \multirow{2}{*}{$\begin{array}{c}A \text { sends } E \$ \\
(1) \\
\end{array}$} & \multirow{2}{*}{$\begin{array}{c}\text { 's } \\
\text { payoff }^{2} E \$ \\
(2)\end{array}$} & \multicolumn{2}{|c|}{$B$ sends $^{3}$} & \multirow{2}{*}{$\begin{array}{c}\text { B's } \\
\text { payoff }^{2,5} E \$ \\
(5)\end{array}$} \\
\hline & & & $\begin{array}{l}\% \\
\text { (3) }\end{array}$ & $\begin{array}{l}E \$^{4} \\
(4)\end{array}$ & \\
\hline Simple (1) & $5.47(3.16)^{1}$ & $11.52(5.71)$ & $0.42(0.26)$ & $7.45(6.86)$ & $19.42(7.97)$ \\
\hline One proposal (2) & $7.69(3.42)$ & $13.89(6.44)$ & $0.49(0.26)$ & $12.70(8.50)$ & $20.86(7.64)$ \\
\hline$\leq$ three proposals (3) & $8.06(3.28)$ & $13.18(7.41)$ & $0.46(0.28)$ & $12.60(8.57)$ & $22.37(8.68)$ \\
\hline $\begin{array}{l}\text { Chat }+ \text { one proposal } \\
\text { (4) }\end{array}$ & $9.20(2.47)$ & $16.63(6.26)$ & $0.59(0.22)$ & $17.18(6.77)$ & $20.96(6.65)$ \\
\hline $\begin{array}{l}\text { Counterpart history } \\
+ \text { one proposal (6) }\end{array}$ & $7.62(3.98)$ & $14.48(7.32)$ & $0.51(0.29)$ & $14.63(8.79)$ & $20.32(8.42)$ \\
\hline
\end{tabular}

Notes:

${ }^{1}$ Numbers in parentheses are standard deviations.

${ }^{2}$ Earnings after deduction of contract costs, where applicable.

${ }^{3}$ Refers to cases in which $A$ sends positive amount.

${ }^{4}$ After tripling $A$ 's sending.

${ }^{5}$ Includes cases in which $A$ sends zero.

Table 2. Average outcomes, interactions 2,3 and 4, by agreement and contract type

\begin{tabular}{|c|c|c|c|c|c|c|}
\hline \multirow{2}{*}{$\begin{array}{l}\text { Agreement or } \\
\text { Contract Type }\end{array}$} & \multirow{2}{*}{$\begin{array}{c}\text { \% of Total } \\
\text { (1) }\end{array}$} & \multirow{2}{*}{$\begin{array}{c}A \text { sends } E \$ \\
\text { (2) }\end{array}$} & \multirow{2}{*}{$\begin{array}{c}A^{\prime} s \text { payoff } \\
\text { (3) } E \$\end{array}$} & \multicolumn{2}{|c|}{$B$ sends ${ }^{3}$} & \multirow{2}{*}{\begin{tabular}{|c|}
$B^{\prime}$ s payoff \\
$E \$$ \\
$(6)$ \\
\end{tabular}} \\
\hline & & & & $\begin{array}{l}\% \\
(4)\end{array}$ & $\begin{array}{c}E \$^{4} \\
(5)\end{array}$ & \\
\hline None & $12.6 \%$ & $4.70(3.41)^{1}$ & $10.11(5.19)$ & $0.32(0.30)$ & $5.76(6.42)$ & $19.30(8.57)$ \\
\hline Agreement only & $71.8 \%$ & $8.83(2.76)$ & $15.39(7.04)$ & $0.53(0.25)$ & $15.06(7.79)$ & $22.28(7.62)$ \\
\hline $\begin{array}{c}\text { Contract } \\
\text { without penalties }\end{array}$ & $9.5 \%$ & $8.11(3.29)$ & $12.66(6.91)$ & $0.50(0.26)$ & $13.17(8.24)$ & $20.70(8.02)$ \\
\hline $\begin{array}{c}\text { Contract } \\
\text { with penalties }\end{array}$ & $6.1 \%$ & $9.89(0.47)$ & $16.94(1.76)$ & $0.68(0.04)$ & $20.14(1.52)$ & $16.39(1.24)$ \\
\hline
\end{tabular}

\section{Notes:}

${ }^{1}$ Numbers in parentheses are standard deviations.

${ }^{2}$ Earnings after deduction of contract costs, where applicable.

${ }^{3}$ Refers to cases in which $A$ sends positive amount.

${ }^{4}$ After tripling $A$ 's sending.

${ }^{5}$ Includes cases in which $A$ sends zero. 
Table 3. Effects of agreement, communication type, and proposal terms

\begin{tabular}{|c|c|c|c|c|}
\hline \multicolumn{5}{|c|}{ Dependent Variable } \\
\hline & $\begin{array}{c}A \text { sends } E \$ \\
\text { (1) }\end{array}$ & $\begin{array}{c}A \text { 's } \\
\text { payoff } E \$ \\
(2)\end{array}$ & $\begin{array}{c}\text { B sends \% } \\
(3) \\
\end{array}$ & $\begin{array}{c}B \text { 's } \\
\text { payoff } E \$ \\
(4)\end{array}$ \\
\hline Sending by $A$ & & & $\begin{array}{l}-0.011 \\
(0.068)\end{array}$ & $\begin{array}{c}1.639 * * * \\
(0.316)\end{array}$ \\
\hline Agreement dummy & $\begin{array}{c}3.161 * * * \\
(0.606)\end{array}$ & $\begin{array}{l}4.370 * * * \\
(1.621)\end{array}$ & $\begin{array}{l}1.051 * * \\
(0.428)\end{array}$ & $\begin{array}{l}-3.804 * \\
(1.993)\end{array}$ \\
\hline$A^{\prime}$ 's row proposal ${ }^{+}$ & $\begin{array}{l}0.221 * \\
(0.117)\end{array}$ & $\begin{array}{l}-0.063 \\
(0312)\end{array}$ & $\begin{array}{l}-0.033 \\
(0.084)\end{array}$ & $\begin{array}{l}0.180 \\
(-.389)\end{array}$ \\
\hline$A^{\prime}$ 's column proposal ${ }^{+}$ & $\begin{array}{c}0.702 * * * \\
(0.258)\end{array}$ & $\begin{array}{c}0.985 \\
(0.690)\end{array}$ & $\begin{array}{c}0.417 * * \\
(0.195)\end{array}$ & $\begin{array}{l}-1.516^{*} \\
(0.909)\end{array}$ \\
\hline $\begin{array}{l}\text { Interaction } 3 \text { dummy } \\
\text { (multiple proposals) }\end{array}$ & $\begin{array}{l}-0.302 \\
(0.343)\end{array}$ & $\begin{array}{l}-1.473 \\
(0.918)\end{array}$ & $\begin{array}{l}-0.353 * \\
(0.218)\end{array}$ & $\begin{array}{c}1.543 \\
(1.015)\end{array}$ \\
\hline $\begin{array}{l}\text { Interaction } 4 \text { dummy } \\
\text { (chat }+ \text { proposal) }\end{array}$ & $\begin{array}{l}0.812 * * \\
(0.812)\end{array}$ & $\begin{array}{l}2.171 * * \\
(0.925)\end{array}$ & $\begin{array}{l}0.382 * \\
(0.225)\end{array}$ & $\begin{array}{l}-1.807 * \\
(1.047)\end{array}$ \\
\hline \# obs. & 294 & 294 & 275 & 275 \\
\hline Wald $\chi^{2}$ & 352.61 & 180.33 & 166.63 & 176.27 \\
\hline Prob. $>\chi^{2}$ & $<0.001$ & $<0.001$ & $<0.001$ & $<0.001$ \\
\hline
\end{tabular}

Notes. GLS regressions, interactions $2-4$ only. Numbers in parentheses are standard errors. All estimates include individual fixed effects. $* * *$ and $* * *$ indicate significance at the $1 \%, 5 \%$, and $10 \%$ levels, respectively. $B$ 's sending and payoff are contingent on $A$ 's sending more than $0 .+$ In multiple-proposal interactions, $A$ 's final proposals. 
Table 4. Effects of agreement, communication type, and proposal terms, excluding interactions conducted under contracts

Dependent Variable

\begin{tabular}{|c|c|c|c|c|}
\hline & $\begin{array}{c}A \text { sends } E \$ \\
\text { (1) }\end{array}$ & $\begin{array}{c}\text { A's } \\
\text { payoff } E \$ \\
\text { (2) }\end{array}$ & $\begin{array}{c}\text { B sends \% } \\
\text { (3) }\end{array}$ & $\begin{array}{c}\text { B's } \\
\text { payoff } E \$ \\
(4)\end{array}$ \\
\hline Sending by $A$ & & & $\begin{array}{l}0.005 \\
(0.076)\end{array}$ & $\begin{array}{c}1.728^{* * *} \\
(0.334)\end{array}$ \\
\hline Agreement dummy & $\begin{array}{c}2.470^{* * *} \\
(0.597)\end{array}$ & $\begin{array}{l}3.857^{* *} \\
(1.723)\end{array}$ & $\begin{array}{l}0.972 * * \\
(0.455)\end{array}$ & $\begin{array}{l}-3.451^{*} \\
(2.009)\end{array}$ \\
\hline$A^{\prime}$ 's row proposal & $\begin{array}{l}0.297 * * \\
(0.124)\end{array}$ & $\begin{array}{l}-0.096 \\
(0.358)\end{array}$ & $\begin{array}{c}0.042 \\
(0.100)\end{array}$ & $\begin{array}{l}-0.035 \\
(0.441)\end{array}$ \\
\hline$A^{\prime}$ 's column proposal ${ }^{+}$ & $\begin{array}{c}0.812 * * * \\
(0.246)\end{array}$ & $\begin{array}{c}0.811 \\
(0.709)\end{array}$ & $\begin{array}{l}0.383^{*} \\
(0.207)\end{array}$ & $\begin{array}{l}-1.150 \\
(0.915)\end{array}$ \\
\hline $\begin{array}{l}\text { Interaction } 3 \text { dummy } \\
\text { (multiple proposals) }\end{array}$ & $\begin{array}{l}-0.130 \\
(0.359)\end{array}$ & $\begin{array}{l}-1.710^{*} \\
(1.038)\end{array}$ & $\begin{array}{l}-0.457^{*} \\
(0.250)\end{array}$ & $\begin{array}{l}2.213^{* *} \\
(1.102)\end{array}$ \\
\hline $\begin{array}{l}\text { Interaction } 4 \text { dummy } \\
(\text { chat }+ \text { proposal) }\end{array}$ & $\begin{array}{l}0.703 * * \\
(0.359)\end{array}$ & $\begin{array}{c}1.664 \\
(1.036)\end{array}$ & $\begin{array}{c}0.281 \\
(0.256)\end{array}$ & $\begin{array}{l}-1.181 \\
(1.130)\end{array}$ \\
\hline \# obs. & 248 & 248 & 231 & 231 \\
\hline Wald $\chi^{2}$ & 433.92 & 188.19 & 167.98 & 202.15 \\
\hline Prob. $>\chi^{2}$ & $<0.001$ & $<0.001$ & $<0.001$ & $<0.001$ \\
\hline
\end{tabular}

Notes. GLS regressions, interactions $2-4$ only. Numbers in parentheses are standard errors. All estimates include individual fixed effects. $*, * *$ and $* * *$ indicate significance at the $1 \%, 5 \%$, and $10 \%$ levels, respectively. $B$ 's sending and payoff are contingent on $A$ 's sending more than $0 . \quad+$ In multiple-proposal interactions, $A$ 's final proposals. 
Table 5. Effects of communication opportunities on sending, returning and payoffs

\begin{tabular}{|c|c|c|c|c|}
\hline & & \multicolumn{3}{|c|}{ Dependent Variable } \\
\hline & $\begin{array}{c}A \text { sends } E \$ \\
\text { (1) }\end{array}$ & $\begin{array}{c}A \text { 's } \\
\text { Payoff } E \$ \\
(2)\end{array}$ & $\begin{array}{c}\text { sends \% } \\
(3) \\
\end{array}$ & $\begin{array}{c}B \text { 's } \\
\text { payoff } E \$ \\
(4)\end{array}$ \\
\hline Sending by $A$ & & & $\begin{array}{c}0.070 \\
(0.043)\end{array}$ & $\begin{array}{c}1.429 * * * \\
(0.187)\end{array}$ \\
\hline $\begin{array}{l}\text { interaction } 2 \text { dummy } \\
\text { (single proposal) }\end{array}$ & $\begin{array}{c}2.131 * * * \\
(0.395) \\
\end{array}$ & $\begin{array}{c}2.662 * * * \\
(0.903)\end{array}$ & $\begin{array}{c}0.244 \\
(0.319) \\
\end{array}$ & $\begin{array}{l}-1.894^{*} \\
(1.058)\end{array}$ \\
\hline $\begin{array}{l}\text { interaction } 3 \text { dummy } \\
\text { ( } \leq 3 \text { proposals) }\end{array}$ & $\begin{array}{c}2.540 * * * \\
(0.397) \\
\end{array}$ & $\begin{array}{l}1.900 * * \\
(0.906)\end{array}$ & $\begin{array}{c}0.006 \\
(0.260)\end{array}$ & $\begin{array}{l}-0.736 \\
(1.125)\end{array}$ \\
\hline $\begin{array}{l}\text { interaction } 4 \text { dummy } \\
\text { (chat }+ \text { proposal) }\end{array}$ & $\begin{array}{c}3.671 * * * \\
(0.398) \\
\end{array}$ & $\begin{array}{c}5.440 * * * \\
(0.909)\end{array}$ & $\begin{array}{l}0.689 * * \\
(0.277)\end{array}$ & $\begin{array}{c}-3.866 * * * \\
(1.198)\end{array}$ \\
\hline No. of observations & 396 & 396 & 371 & 371 \\
\hline Wald $\chi^{2}$ & 292.73 & 162.16 & 132.84 & 218.51 \\
\hline Prob. $>\chi^{2}$ & $<0.001$ & $<0.001$ & 0.026 & $<0.001$ \\
\hline
\end{tabular}

Notes. Numbers in parentheses are standard errors. All estimates are by GLS and include individual fixed effects. $*, * *$ and $* * *$ indicate significance at the $1 \%, 5 \%$, and $10 \%$ levels, respectively. B's sending and payout are contingent on A's sending more than 0 . All observations from interactions 1, 2, 3 and 4 are included. 
Table 6. GLS regressions of effects of two contract types on sending, returning and earning, given agreement

\begin{tabular}{|c|c|c|c|c|}
\hline & \multicolumn{4}{|c|}{ Dependent Variable } \\
\hline & A row select & A round payout & B column select & B round payout \\
\hline Sending by $A$ & & & $\begin{array}{c}0.012 \\
(0.079) \\
\end{array}$ & $\begin{array}{c}1.529 * * * \\
(0.376) \\
\end{array}$ \\
\hline $\begin{array}{l}\text { A's row } \\
\text { proposal }\end{array}$ & $\begin{array}{c}0.067 \\
(0.195) \\
\end{array}$ & $\begin{array}{c}0.087 \\
(0.559) \\
\end{array}$ & $\begin{array}{c}0.011 \\
(0.130)\end{array}$ & $\begin{array}{c}0.173 \\
(0.618) \\
\end{array}$ \\
\hline $\begin{array}{l}\text { A's column } \\
\text { proposal }^{+}\end{array}$ & $\begin{array}{c}0.201 \\
(0.791)\end{array}$ & $\begin{array}{c}2.109 \\
(2.267)\end{array}$ & $\begin{array}{c}0.390 \\
(0.515)\end{array}$ & $\begin{array}{l}-3.044 \\
(2.450)\end{array}$ \\
\hline $\begin{array}{l}\text { Contract w/o } \\
\text { penalty dummy }\end{array}$ & $\begin{array}{c}0.583 \\
(0.596)\end{array}$ & $\begin{array}{c}2.218 \\
(1.709)\end{array}$ & $\begin{array}{c}0.341 \\
(0.396)\end{array}$ & $\begin{array}{l}-3.552^{*} \\
(1.885)\end{array}$ \\
\hline $\begin{array}{l}\text { Contract with } \\
\text { penalty dummy }\end{array}$ & $\begin{array}{c}2.745^{* * * *} \\
(0.715)\end{array}$ & $\begin{array}{c}7.442 * * * \\
(2.049)\end{array}$ & $\begin{array}{c}1.549^{* * * *} \\
(0.481)\end{array}$ & $\begin{array}{c}-10.359^{* * * *} \\
(2.290)\end{array}$ \\
\hline $\begin{array}{l}\text { interaction } 3 \\
\text { dummy } \\
\text { ( } \leq 3 \text { proposals) }\end{array}$ & $\begin{array}{c}-0.343 \\
(0.352)\end{array}$ & $\begin{array}{l}-1.189 \\
(1.008)\end{array}$ & $\begin{array}{l}-0.314 \\
(0.223)\end{array}$ & $\begin{array}{c}1.508 \\
(1.059)\end{array}$ \\
\hline $\begin{array}{l}\text { interaction } 4 \\
\text { dummy } \\
\text { (chat }+ \text { prop.) }\end{array}$ & $\begin{array}{c}0.482 \\
(0.374)\end{array}$ & $\begin{array}{c}1.747 \\
(1.072)\end{array}$ & $\begin{array}{c}0.307 \\
(0.240)\end{array}$ & $\begin{array}{c}-1.466 \\
(1.141)\end{array}$ \\
\hline \# obs. & 257 & 257 & 244 & 244 \\
\hline Wald $\chi^{2}$ & 267.30 & 170.88 & 162.27 & 186.60 \\
\hline Prob. $>\chi^{2}$ & $<0.001$ & $<0.001$ & $<0.001$ & $<0.001$ \\
\hline
\end{tabular}

Notes. Numbers in parentheses are standard errors. All estimates are by GLS and include individual fixed effects. *, ** and $* * *$ indicate significance at the $1 \%, 5 \%$, and $10 \%$ levels, respectively. Column 3 and 4 estimates include only cases in which $A$ sent more than 0 . Only observations from interactions 2,3 and 4 in which agreements were reached are included. 